\title{
Wind-induced vibration analysis of the Hong Kong Ting Kau Bridge
}

C. Su*, D. J. Han*, Q. S. Yan*, F. T. K. Au ${ }^{\dagger}$, L. G. Tham ${ }^{\dagger}$, P. K. K. Lee ${ }^{\dagger}$, K. M. Lam ${ }^{\dagger}$ and K. Y. Wong

Because of their high flexibility and relatively low structural damping, long-span bridges are prone to windinduced vibration. An efficient wind field simulation technique for wind-induced vibration analysis of long-span bridges is first introduced in this paper. The time-domain expressions for the buffeting and self-excited forces acting on long-span bridges can then be found from the wind velocities. Based on the above theory and the aerodynamic parameters obtained by wind tunnel tests, a study of the wind fluctuations and aerodynamic forces is carried out on the Hong Kong Ting Kau Bridge, which is a cable-stayed bridge comprising two main spans and two side spans. The buffeting response of the bridge is analysed in the time domain by using step-by-step numerical integration techniques. The aerodynamic behaviour of the bridge can therefore be obtained, and the safety performance of the bridge against strong wind can further be evaluated. Numerical results basically agree with the experimental data, indicating that the theory presented in this paper is applicable to engineering practice.

\section{NOTATION}

$A_{\mathrm{i}}^{*} \quad$ torsional aerodynamic derivatives $(i=1,2,3,4)$

$A_{\text {ilk }} \quad$ amplitude of wind turbulence

$B \quad$ deck width

$C_{\mathrm{L}}, C_{\mathrm{D}}, C_{\mathrm{M}}$ non-dimensional static coefficients

$C_{\mathrm{iF} \delta} \quad$ transfer function constants

$$
(i=1,2, \Lambda, 6 ; F=M, L ; \delta=\alpha, h)
$$

$C_{\mathrm{y}} \quad$ exponential decay coefficient

$\boldsymbol{D}_{\mathrm{st}}, \boldsymbol{D}_{\mathrm{bf}} \quad$ static and buffeting drag forces per unit span length respectively

$F_{\mathrm{M} \alpha}, F_{\mathrm{Mh}}, \quad$ transfer functions

$F_{\mathrm{L} \alpha}, F_{\mathrm{Lh}}$

$f_{\mathrm{M} \alpha}, f_{\mathrm{Mh}}$,

$f_{\mathrm{L} \alpha}, f_{\mathrm{Lh}}$

impulse response functions

$[H]$

lower triangular matrix by Cholesky decomposition of $[S]$

$H_{\mathrm{il}} \quad$ the $(i, l)$ th entry of $[H]$

$H_{\mathrm{i}}^{*} \quad$ vertical aerodynamic derivatives $(i=1,2,3,4)$

* Department of Civil Engineering, South China University of Technology, Guangzhou, China

$\dagger$ Department of Civil Engineering, University of Hong Kong, China

* Tsing Ma Control Area Division, Highways Department, Government of the

Hong Kong SAR, China $h \quad$ vertical translation of deck

$I_{\mathrm{u}}, I_{\mathrm{w}} \quad$ intensity of wind turbulence

$\boldsymbol{L}_{\mathrm{st}}, \boldsymbol{L}_{\mathrm{bf}}, \boldsymbol{L}_{\mathrm{se}}$ static, buffeting and self-excited lift forces per unit span length respectively

$L_{\mathrm{x}}^{\mathrm{u}}, L_{\mathrm{x}}^{\mathrm{w}} \quad$ integral scales of wind turbulence

$\boldsymbol{M}_{\mathrm{st}}, \boldsymbol{M}_{\mathrm{bf}}$, static, buffeting and self-excited torque moments

$\boldsymbol{M}_{\mathrm{se}} \quad$ per unit span length respectively

$m \quad$ number of wind velocity processes on deck

$N \quad$ number of frequency intervals

$n \quad$ frequency in hertz

$S \quad$ auto-spectral density function

$S_{\mathrm{ij}} \quad$ cross-spectral density function

$[S] \quad$ spectral density matrix

$S_{\mathrm{u}}, S_{\mathrm{w}} \quad$ auto-spectral density functions of wind turbulence $t \quad$ time

$U, V, W$ wind velocities

$U_{\mathrm{m}} \quad$ mean wind velocity

$u, v, w \quad$ fluctuating components of $U, V$ and $W$

$x, y, z \quad$ Cartesian coordinates

$\Delta y \quad$ distance between two adjacent process locations

$\alpha \quad$ twist angle of deck

$\theta \quad$ attack angle of wind

$\theta_{\mathrm{il}} \quad$ argument of $H_{\mathrm{il}}$

$v \quad$ reduced wind velocity

$\rho \quad$ air density

$\sigma_{\mathrm{u}}, \sigma_{\mathrm{w}} \quad$ standard deviations of wind turbulence

$\tau \quad$ time

$\phi_{\mathrm{lk}} \quad$ independent random phase angle uniformly

distributed between 0 and $2 \pi$

$\omega \quad$ circular frequency

$\omega_{\mathrm{k}} \quad$ the $k$ th circular frequency

$\omega_{\max }, \omega_{\min }$ upper and lower frequency limits

$\Delta \omega \quad$ increment of circular frequency

\section{INTRODUCTION}

The Ting Kau Bridge ${ }^{1}$ in Hong Kong (Fig. 1) is a cable-stayed bridge comprising two main spans and two side spans. The bridge deck is supported by three towers, an end pier and an abutment. Each of the three towers consists of a single reinforced concrete mast that reduces its section in steps, and it is strengthened by transverse cables and struts in the transverse vertical plane. The bridge deck is supported by four inclined planes of cables emanating from anchorages at the tower tops. Fig. 2 shows a simplified finite-element model of the bridge in 


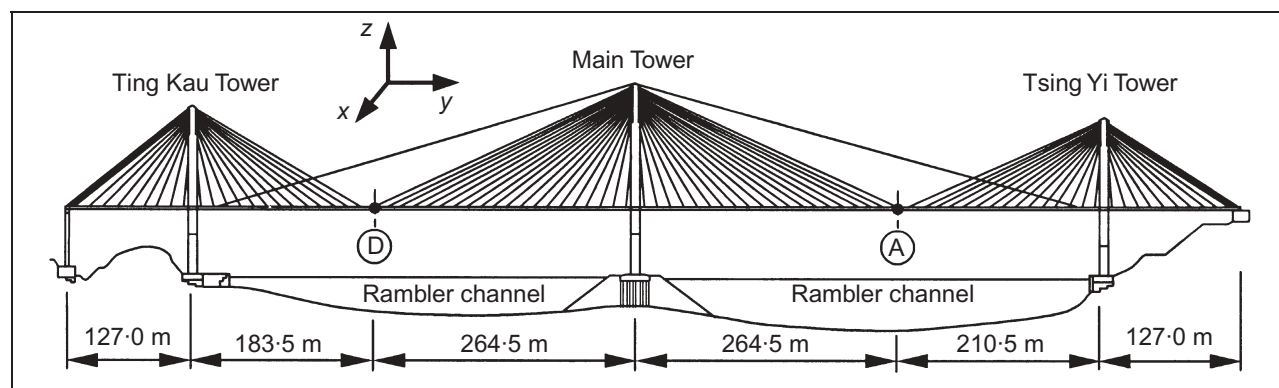

Fig. I. Elevation of Ting Kau Bridge showing the sections of bridge deck studied

\section{SIMULATION OF WIND FIELD FOR LONG-SPAN BRIDGES}

To perform analysis of windinduced vibration by the time domain approach, one needs to simulate the wind velocity time histories at various locations along the bridge span based on a set of wind spectral density functions. The simulation of the wind field is the basis for time

which each carriageway is represented by a triple-girder model. Situated in an area of complex topography, the bridge is susceptible to typhoon attack during its lifetime. The purpose of the present study is to establish the relationships between the wind action and the bridge response through a numerical method so as to assess the aerodynamic behaviour of the bridge.

The dynamic response of a bridge under stochastic wind loads can be studied either in the frequency domain or in the time domain. Based on the stochastic vibration theory, Davenport ${ }^{2}$ first developed an approach for wind response analysis in the frequency domain considering buffeting loads only. On this basis, Simiu and Scanlan ${ }^{3}$ established a theoretical framework for analysis of both the buffeting and the fluttering responses in the frequency domain using the aerodynamic derivatives concept and the quasi-steady theory. In this method both the buffeting and the self-excited forces are taken into consideration. The frequency domain method mentioned above is based on the linear hypothesis, and hence the total response is obtained by a combination of the contributions from all the vibration modes. This assumption, however, is not appropriate for long-span bridges, where non-linearity due to either geometric or aeroelastic effects must be considered. As an alternative method, the non-linear response of long-span bridges can be analysed in the time domain by using step-by-step numerical integration techniques. ${ }^{4,5}$

The first objective of the present study is to model the wind fluctuations along the bridge span with temporal and spatial correlations. This then helps us to establish the aerodynamic forces acting on the bridge deck based on the given wind data and the aerodynamic parameters of the bridge deck section. The second objective is to carry out a non-linear analysis of the responses in the time domain using a suitable threedimensional structural model that takes into account both the geometric non-linearity and the aerodynamic coupling between wind action and structural responses.

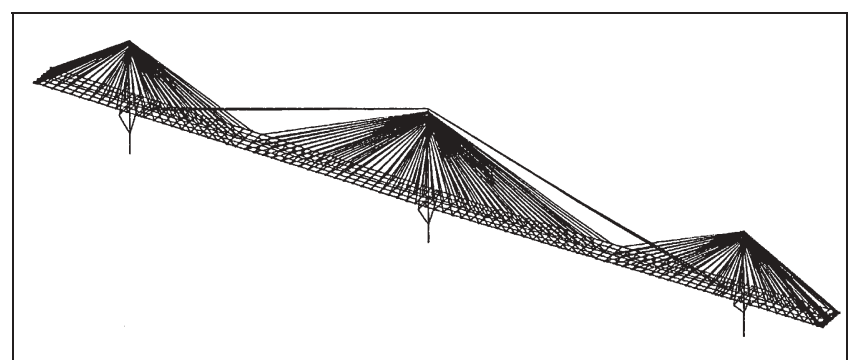

Fig. 2. Simplified finite-element model of Ting Kau Bridge domain formulation of the aerodynamic forces acting on bridges.

\section{I. Simulation of wind turbulence with temporal-spatial correlations}

The spectral representation method is one of the most commonly used methods for simulation of multidimensional random processes with a specified cross-spectral density matrix. It has been shown by Shinozuka and his associates ${ }^{6,7}$ that a set of $m$ stationary Gaussian random processes $u_{\mathrm{i}}^{0}(t)$ $(i=1,2, \ldots, m)$ with zero means and one-sided target crossspectral density matrix $[S]$ can be simulated by the following equations

\begin{tabular}{|l|l|}
$u_{\mathrm{i}}(t)=\sum_{l=1}^{m} \sum_{k=1}^{N}\left|H_{\mathrm{il}}\left(\omega_{\mathrm{k}}\right)\right| \sqrt{2 \Delta \omega} \cos \left[\omega_{\mathrm{k}} t+\theta_{\mathrm{il}}\left(\omega_{\mathrm{k}}\right)+\phi_{\mathrm{lk}}\right]$ \\
for $i=1,2, \ldots, m$
\end{tabular}

where

\begin{tabular}{|l|l|}
\hline 2 & $\Delta \omega=\frac{\omega_{\max }-\omega_{\min }}{N}$ \\
$\omega_{\mathrm{k}}$ & $=\omega_{\min }+\left(k-\frac{1}{2}\right) \Delta \omega$ \\
\hline
\end{tabular}

In the above equations, $N$ is the number of frequency intervals; $\omega_{\max }$ and $\omega_{\min }$ are the upper and lower frequency limits; $\phi_{\mathrm{lk}}$ is the independent random phase angles uniformly distributed between 0 and $2 \pi ; H_{\mathrm{il}}$ is the $(i, l)$ entry of the lower triangular matrix $[H]$, which is determined by Cholesky decomposition of the cross-spectral density matrix $[S]$; and $\theta_{\mathrm{il}}$ is the argument of $H_{\mathrm{il}}$. Owing to the repetitive decomposition of the cross-spectral density matrix $[S]$, the computation for the conventional spectral representation method could be very time-consuming when a large number of wind velocity time histories have to be simulated, as is often the case for aerodynamic analysis of long-span bridges in the time domain.

In view of the above problem, Yang et al. ${ }^{8}$ developed an efficient wind field simulation technique for bridges based on the original spectral representation method under certain assumptions. Consider $m$ wind velocity processes, denoted as $u_{\mathrm{i}}(t)(i=1,2, \ldots, m)$, acting at $m$ locations equally distributed along the spanwise direction of a bridge, as illustrated in Fig. 3. It is assumed that the bridge deck is at the same elevation and the wind field is homogeneous along the 
bridge span. It is further assumed that the locations at which the wind velocity processes act are equally distributed along the axial direction of the bridge. Then the cross-spectral density function between wind turbulence $u_{\mathrm{i}}(t)$ at location $i$ and $u_{\mathrm{j}}(t)$ at location $j$ can be written as

$$
3 \quad S_{\mathrm{ij}}(\omega)=S(\omega)(\cos \beta)^{\mathrm{j}-\mathrm{i}} \quad(j \geqslant i ; i, j=1,2, \ldots, m)
$$

where

\begin{tabular}{|l|l|}
\hline 4 & $\cos \beta=\exp \left(-\frac{n C_{\mathrm{y}} \Delta y}{U_{\mathrm{m}}}\right)$ \\
\hline
\end{tabular}

In the above equations, $S(\omega)$ is the auto-spectral density function; $U_{\mathrm{m}}$ is the mean wind velocity at the bridge deck level; $\Delta y$ is the distance between two adjacent process locations; and $C_{\mathrm{y}}$ is the exponential decay coefficient. Using equations (3) and (4), the Cholesky decomposition of the crossspectral density matrix $[S]$ can be explicitly derived, ${ }^{8}$ and therefore equation (1) can be rewritten as

\begin{tabular}{|l|l|}
\hline 5 & $u_{\mathrm{i}}(t)=\sum_{k=1}^{N} \sum_{l=1}^{i} A_{\mathrm{ilk}} \cos \left(\omega_{\mathrm{k}} t+\phi_{\mathrm{lk}}\right)$ for $i=1,2, \ldots, m$ \\
\hline
\end{tabular}

where

$$
\begin{aligned}
6 & A_{\mathrm{ilk}}=\sqrt{2 \Delta \omega S\left(\omega_{\mathrm{k}}\right)} \alpha_{1}(\cos \beta)^{\mathrm{i}-1} \quad a_{1}=1 \text { for } l=1, \\
& a_{1}=\sin \beta \text { for } l>1
\end{aligned}
$$

It is evident that equation (5) requires less computational effort than the original spectral representation (equation (1)), since no Cholesky decomposition is required in the current approach.

\subsection{Simulation of wind turbulence for Ting Kau Bridge}

A rectangular Cartesian coordinates system $(x, y, z)$ is so chosen that the $y$-axis is in the axial direction, the $z$-axis is vertical, and the $x$-axis is in the lateral direction, as illustrated in Fig. 3. Let the along-wind direction be in the $x$ direction. Then the components $U, V$ and $W$ of the wind velocity field in, respectively, the along-wind, across-wind and vertical directions along the bridge deck can be expressed as follows

$$
\begin{aligned}
\boldsymbol{U}(y, z, t) & =\boldsymbol{U}_{\mathrm{m}}(z)+u(y, z, t) \\
\boldsymbol{V}(y, z, t) & =v(y, z, t) \\
\boldsymbol{W}(y, z, t) & =w(y, z, t)
\end{aligned}
$$

where $U_{\mathrm{m}}$ is the mean wind velocity of $U$ at elevation $z$; and $u, v$ and $w$ are the corresponding fluctuating components of $\boldsymbol{U}$, $\boldsymbol{V}$ and $\boldsymbol{W}$. In practical engineering applications, the wind turbulence $(u, v, w)$ can be considered as stationary Gaussian random processes with zero means, and therefore they can be simulated using the techniques discussed in the previous section. Since the effect of the across-wind turbulence, $v(t)$, on buffeting forces is usually negligible, ${ }^{3}$ only the along-wind turbulence, $u(t)$, and the vertical turbulence, $w(t)$, are generated in the present simulation.

The reliability of the generated wind fluctuations depends primarily on the assumed wind spectra and the corresponding wind characteristics, which need to be chosen carefully. As no reliable measurements of turbulence spectra are available for the bridge site, the Engineering Sciences Data Unit (ESDU) Spectra $^{9}$ are recommended for simulation of the wind field for the Ting Kau Bridge. ${ }^{10}$ In accordance with these recommendations, the empirical expressions for the along-wind and vertical spectra are respectively

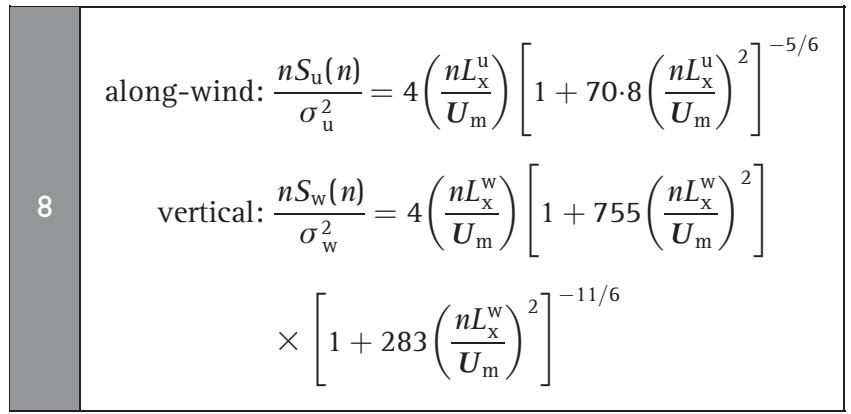

where $n$ is the frequency in hertz; $S_{\mathrm{u}}$ and $S_{\mathrm{w}}$ are the autospectral density functions of the wind turbulence; $\sigma_{\mathrm{u}}$ and $\sigma_{\mathrm{w}}$ are the standard deviations of the wind turbulence; $L_{\mathrm{x}}^{\mathrm{u}}$ and $L_{\mathrm{x}}^{\mathrm{w}}$ are the integral scales of the wind turbulence in the $x$ direction; and $U_{\mathrm{m}}$ is the mean wind velocity in the along-wind direction. The wind cross-spectra can then be determined by equations (3) and (4), in which the exponential decay coefficient, $C_{\mathrm{y}}$, is taken to be 16 as suggested in Reference 3 for engineering applications. The wind characteristics at the deck level of Ting Kau Bridge, at an approximate height of $70 \mathrm{~m}$ above sea level, are summarised in Table 1 , as suggested by a review of the available wind data. $^{10}$

The wind field at the deck of Ting Kau Bridge can be characterised by the turbulent wind velocities acting on a total of 87 stations on the deck at a regular spacing of $13.5 \mathrm{~m}$. They are numbered 


\begin{tabular}{|lrllll|}
\hline $\begin{array}{l}\text { Return period: } \\
\text { years }\end{array}$ & $U_{\mathrm{m}}: \mathrm{m} / \mathrm{s}$ & $I_{u}$ & $I_{\mathrm{w}}$ & $\sigma_{u}: \mathrm{m} / \mathrm{s}$ & $\sigma_{w}: \mathrm{m} / \mathrm{s}$ \\
\hline 50 & $45 \cdot 60$ & 0.1048 & 0.0865 & 4.779 & 3.944 \\
120 & 53.57 & 0.1048 & 0.0865 & 5.614 & 4.634 \\
\hline
\end{tabular}

sequentially from 1 at the Ting Kau end to 87 at the Tsing Yi end, as illustrated in Fig. 3. In the present study, the sampling time interval is $0.2 \mathrm{~s}$ and the number of time steps is 1000 , with a total duration of $200 \mathrm{~s}$. The number of frequency steps is assumed to be 1000 with a cut-off frequency of $2 \mathrm{~Hz}$, which is broad enough to contain the wind turbulence energy as well as the first 20 vibration frequencies of the bridge. Using the mean wind velocity $U_{\mathrm{m}}=45.60 \mathrm{~m} / \mathrm{s}$ for a return period of 50 years, the fluctuating components $u(t)$ and $w(t)$ in the along-wind and vertical directions respectively at various stations along the bridge deck are simulated. The results at selected stations for fluctuating components $u(t)$ and $w(t)$ are shown in Figs 4 and 5 respectively.

\section{FORMULATION OF AERODYNAMIC FORCES ON BRIDGE DECK}

A prerequisite for the aerodynamic analysis of a bridge structure by the time domain approach is to establish expressions for the fluctuating wind load histories acting on the bridge deck. The aerodynamic forces consist of three parts: the static forces due to the mean wind, the buffeting forces due to wind turbulence, and the self-excited forces due to aeroelasticity. The formulations of the above forces acting on the deck of Ting Kau Bridge are briefly summarised below.
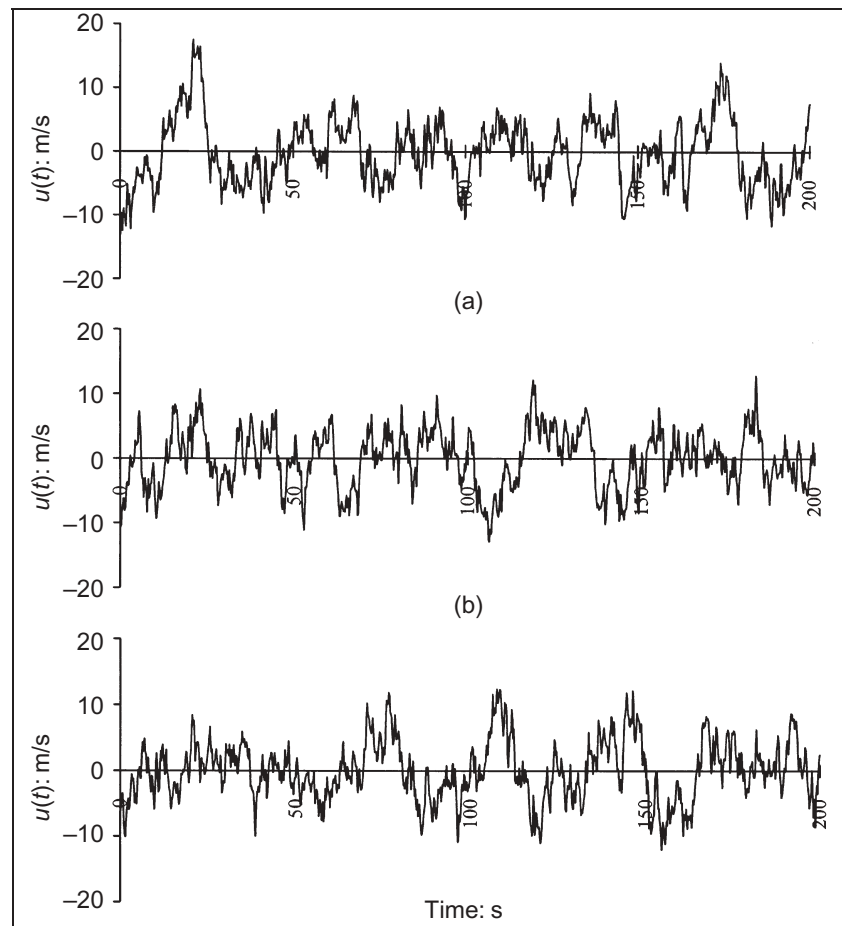

(c)

Fig. 4. Fluctuating wind velocity component, $u(t)$, under mean wind velocity, $U_{m}=45.60 \mathrm{~m} / \mathrm{s}$ of 50 -year return period: (a) at Station 20; (b) at Station 30; (c) at Station 50

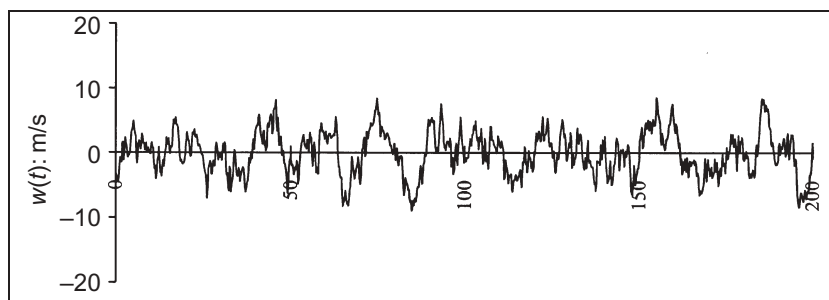

(a)

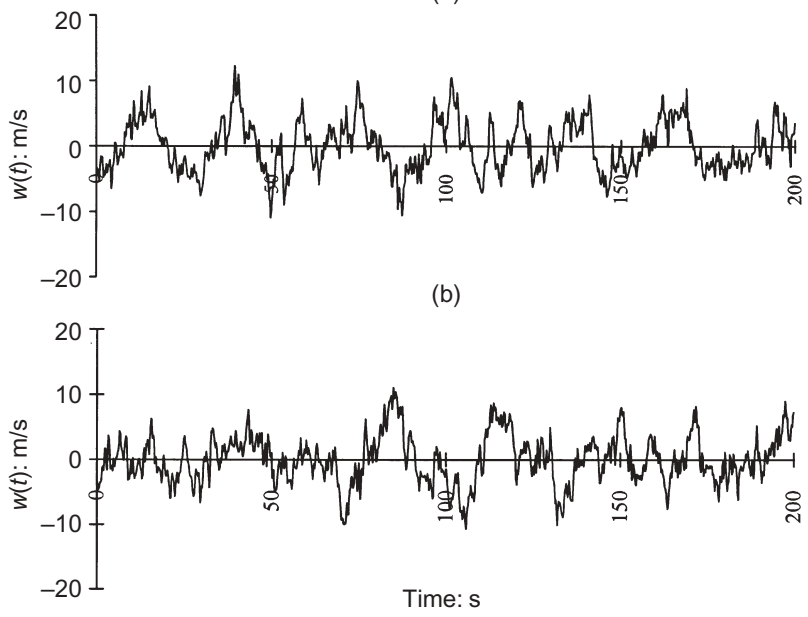

(c)

Fig. 5. Fluctuating wind velocity component, $w(t)$, under mean wind velocity, $U_{m}=45.60 \mathrm{~m} / \mathrm{s}$ of 50 -year return period: (a) at Station 20; (b) at Station 30; (c) at Station 50

\section{I. Equivalent static forces due to mean wind velocity}

The mean wind-induced forces on a bridge deck should be determined by wind tunnel tests of a section model. According to the wind tunnel report, ${ }^{11}$ the static forces on the Ting Kau Bridge deck due to mean wind are expressed as follows

\begin{aligned} & $\boldsymbol{L}_{\mathrm{st}}=\frac{1}{2} \rho \boldsymbol{U}_{\mathrm{m}}^{2} C_{\mathrm{L}} B \\ & \boldsymbol{D}_{\mathrm{st}}=\frac{1}{2} \rho \boldsymbol{U}_{\mathrm{m}}^{2} C_{\mathrm{D}} B \\ & \boldsymbol{M}_{\mathrm{st}}=\frac{1}{2} \rho \boldsymbol{U}_{\mathrm{m}}^{2} C_{\mathrm{M}} B^{2} \\ &$\hline\end{aligned}

where $\boldsymbol{L}_{\mathrm{st}}, \boldsymbol{D}_{\mathrm{st}}$ and $\boldsymbol{M}_{\mathrm{st}}$ are respectively the static lift, drag and torque moment on the deck per unit span length; $\rho$ is the air density; $U_{\mathrm{m}}$ is the mean wind velocity at the deck level; $B$ is the deck width; and $C_{\mathrm{L}}, C_{\mathrm{D}}$ and $C_{\mathrm{M}}$ are the respective nondimensional static coefficients, which can be extracted from the above wind tunnel report.

The equivalent static forces on the cables and various components of the towers due to mean wind velocity are estimated by the same approach using the corresponding nondimensional static coefficients recommended by the wind tunnel report; ${ }^{11}$ the buffeting forces and self-induced forces on these components are ignored.

\subsection{Buffeting forces due to wind turbulence}

After the determination of wind velocity time histories, the buffeting forces due to wind turbulence can be obtained by the following equations ${ }^{12,13}$ 


$$
\begin{aligned}
\boldsymbol{L}_{\mathrm{bf}} & =-\frac{1}{2} \rho \boldsymbol{U}_{\mathrm{m}}^{2} B\left[C_{\mathrm{L}} \frac{2 u}{\boldsymbol{U}_{\mathrm{m}}}+\left(\frac{\mathrm{d} C_{\mathrm{L}}}{\mathrm{d} \theta}+C_{\mathrm{D}}\right) \frac{w}{\boldsymbol{U}_{\mathrm{m}}}\right] \\
\boldsymbol{D}_{\mathrm{bf}} & =\frac{1}{2} \rho \boldsymbol{U}_{\mathrm{m}}^{2} B\left(C_{\mathrm{D}} \frac{2 u}{\boldsymbol{U}_{\mathrm{m}}}+\frac{\mathrm{d} C_{\mathrm{D}}}{\mathrm{d} \theta} \frac{w}{\boldsymbol{U}_{\mathrm{m}}}\right) \\
\boldsymbol{M}_{\mathrm{bf}} & =\frac{1}{2} \rho \boldsymbol{U}_{\mathrm{m}}^{2} B^{2}\left(C_{\mathrm{M}} \frac{2 u}{\boldsymbol{U}_{\mathrm{m}}}+\frac{\mathrm{d} C_{\mathrm{M}}}{\mathrm{d} \theta} \frac{w}{\boldsymbol{U}_{\mathrm{m}}}\right)
\end{aligned}
$$

where $\boldsymbol{L}_{\mathrm{bf}}, \boldsymbol{D}_{\mathrm{bf}}$ and $\boldsymbol{M}_{\mathrm{bf}}$ are respectively the buffeting lift, drag and torque moment per unit span length; $C_{\mathrm{L}}, C_{\mathrm{D}}$ and $C_{\mathrm{M}}$ are the respective non-dimensional static coefficients as defined previously; and $\theta$ is the attack angle of wind. The time histories of buffeting lift force and torque acting at the middle of the span between the Ting Kau Tower and the Main Tower are shown in Fig. 6.

\subsection{Self-excited forces due to aeroelastic effects}

Because of the high degree of flexibility of a long-span bridge, it is subjected not only to the static forces due to the mean wind and the buffeting forces due to the wind turbulence, but also to the forces caused by the motion of the bridge itself, which are known as self-excited forces. They play an important role in the wind-induced vibration of a long-span bridge, and may cause aeroelastic instability of the bridge under certain circumstances.

The common formulation for expressing the self-excited forces on a bridge deck using aerodynamic derivatives is a mixed form of time and frequency domains, ${ }^{14}$ and it is not suitable for aerodynamic analysis of the bridge by the time domain method. In the present study, the response function formulation developed by Bucher and Lin $^{15}$ is adopted to establish the time-domain expressions of the self-excited forces acting on the bridge deck. The self-excited torque, $\boldsymbol{M}_{\mathrm{se}}$, and self-excited lift force, $\boldsymbol{L}_{\mathrm{se}}$, per unit span length can be expressed respectively in terms of convolution integrals as follows ${ }^{15}$
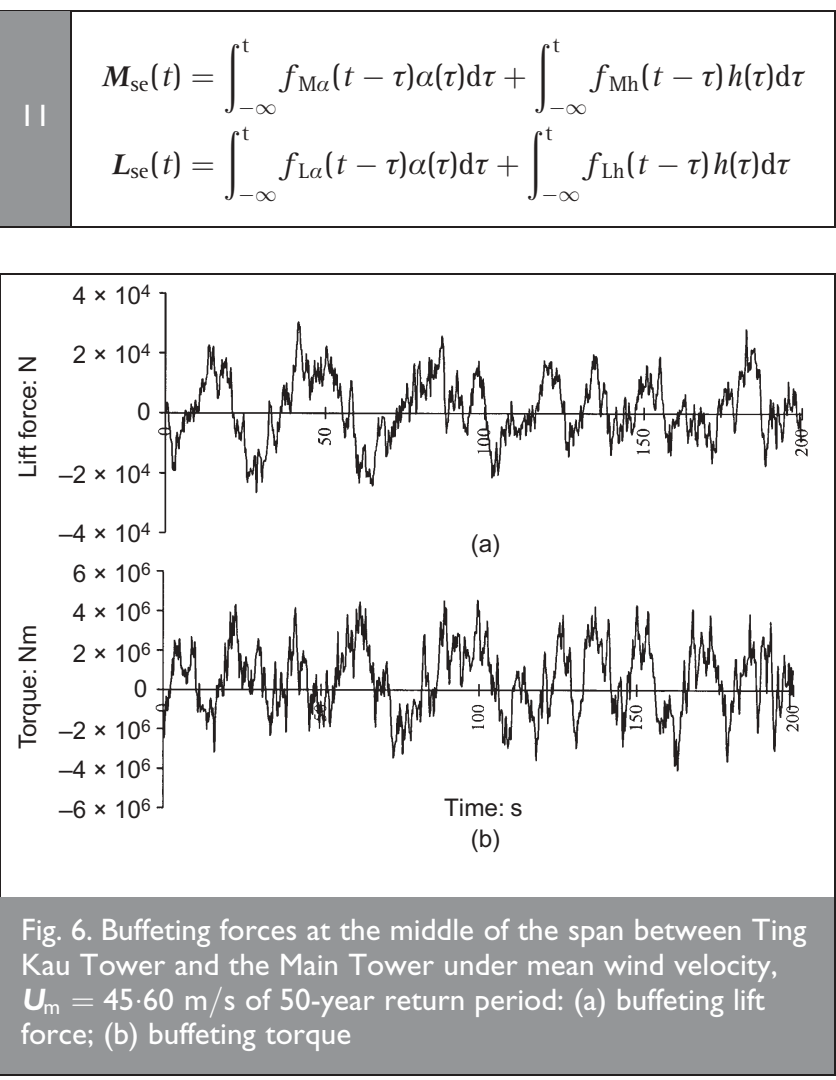

where $\alpha$ and $h$ are, respectively, the twist angle and vertical translation of the deck, and the $f$ functions are the impulse response functions corresponding to the degrees of freedom indicated by the subscripts in which $M$ and $L$ respectively represent the torque and lift force respectively. The Fourier transforms of the $f$ functions are the transfer functions, and they can be rationally taken as ${ }^{15}$

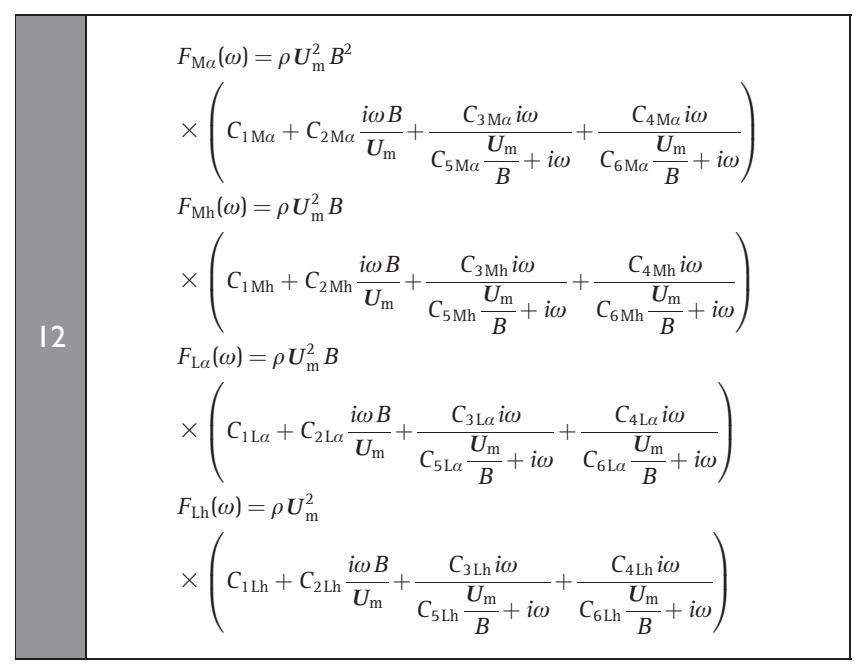

where $\omega$ is the angular frequency, and the $C$ coefficients are the non-dimensional constants of the transfer functions to be identified from the wind tunnel test data. Performing inverse Fourier transforms of equation (12) and then integrating equation (11) leads to the self-excited forces expressed in the time domain as follows

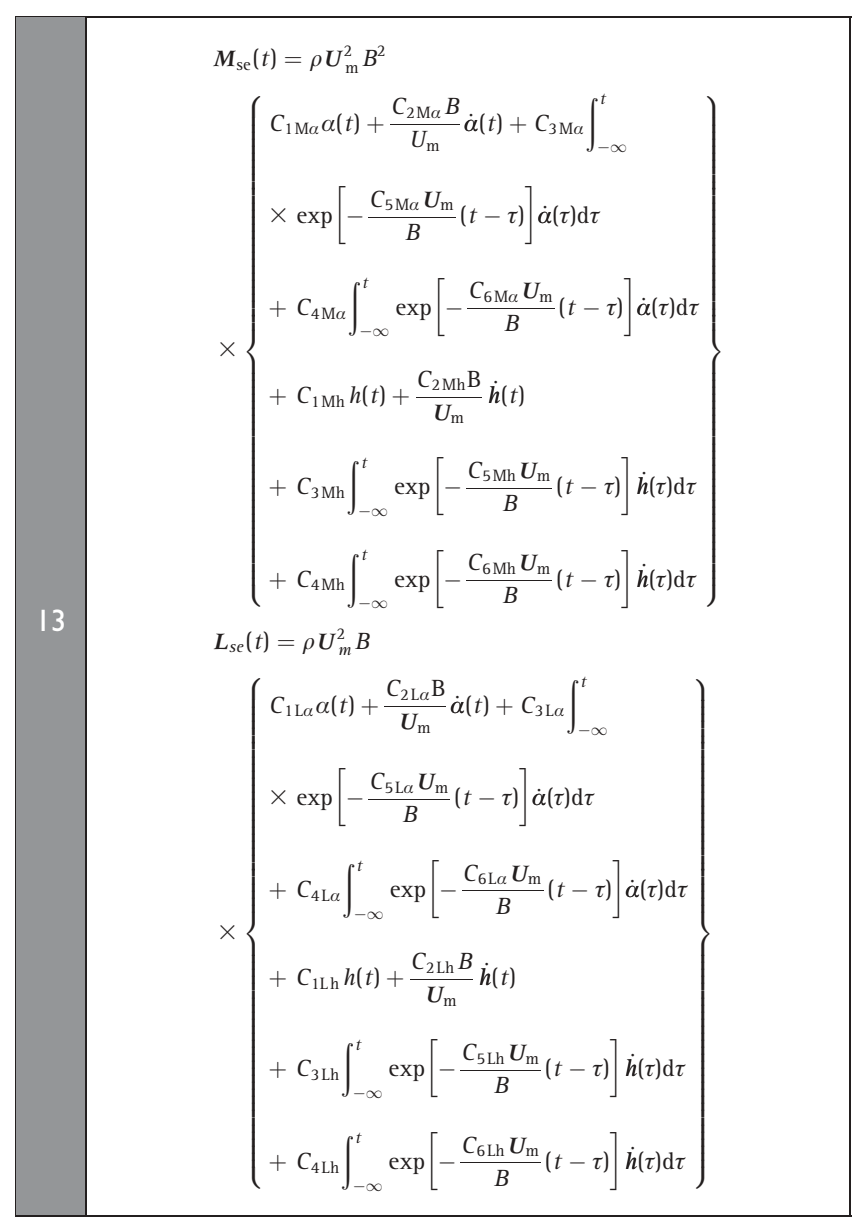


In the above equations, the $C$ coefficients need to be identified from the aerodynamic derivatives by certain non-linear parameter identification techniques. The relationships between the aerodynamic derivatives and the $C$ coefficients are ${ }^{15}$

$$
\begin{aligned}
& \begin{array}{|l}
\hline \\
14
\end{array} \\
& A_{1}^{*}=\frac{v}{2 \pi}\left(C_{2 \mathrm{Mh}}+\frac{C_{3 \mathrm{Mh}} C_{5 \mathrm{Mh}} \boldsymbol{v}^{2}}{C_{5 \mathrm{Mh}}^{2} \boldsymbol{v}^{2}+4 \pi^{2}}+\frac{C_{4 \mathrm{Mh}} C_{6 \mathrm{Mh}} \boldsymbol{v}^{2}}{C_{6 \mathrm{Mh}}^{2} \boldsymbol{v}^{2}+4 \pi^{2}}\right) \\
& A_{2}^{*}=\frac{v}{2 \pi}\left(C_{2 \mathrm{M} \alpha}+\frac{C_{3 \mathrm{M} \alpha} C_{5 \mathrm{M} \alpha} v^{2}}{C_{5 \mathrm{M} \alpha}^{2} v^{2}+4 \pi^{2}}+\frac{C_{4 \mathrm{M} \alpha} C_{6 \mathrm{M} \alpha} v^{2}}{C_{6 \mathrm{M} \alpha}^{2} v^{2}+4 \pi^{2}}\right) \\
& A_{3}^{*}=v^{2}\left(\frac{C_{1 \mathrm{M} \alpha}}{4 \pi^{2}}+\frac{C_{3 \mathrm{M} \alpha}}{C_{5 \mathrm{M} \alpha}^{2} v^{2}+4 \pi^{2}}+\frac{C_{4 \mathrm{M} \alpha}}{C_{6 \mathrm{M} \alpha}^{2} v^{2}+4 \pi^{2}}\right) \\
& A_{4}^{*}=\boldsymbol{v}^{2}\left(\frac{C_{1 \mathrm{Mh}}}{4 \pi^{2}}+\frac{C_{3 \mathrm{Mh}}}{C_{5 \mathrm{Mh}}^{2} \boldsymbol{v}^{2}+4 \pi^{2}}+\frac{C_{4 \mathrm{Mh}}}{C_{6 \mathrm{Mh}}^{2} \boldsymbol{v}^{2}+4 \pi^{2}}\right) \\
& H_{1}^{*}=\frac{v}{2 \pi}\left(C_{2 \mathrm{Lh}}+\frac{C_{3 \mathrm{Lh}} C_{5 \mathrm{Lh}} \boldsymbol{v}^{2}}{C_{5 \mathrm{Lh}}^{2} \boldsymbol{v}^{2}+4 \pi^{2}}+\frac{C_{4 \mathrm{Lh}} C_{6 \mathrm{Lh}} v^{2}}{C_{6 \mathrm{Lh}}^{2} \boldsymbol{v}^{2}+4 \pi^{2}}\right) \\
& H_{2}^{*}=\frac{v}{2 \pi}\left(C_{2 \mathrm{~L} \alpha}+\frac{C_{3 \mathrm{~L} \alpha} C_{5 \mathrm{~L} \alpha} v^{2}}{C_{5 \mathrm{~L} \alpha}^{2} v^{2}+4 \pi^{2}}+\frac{C_{4 \mathrm{~L} \alpha} C_{6 \mathrm{~L} \alpha} v^{2}}{C_{6 \mathrm{~L} \alpha}^{2} v^{2}+4 \pi^{2}}\right) \\
& H_{3}^{*}=\boldsymbol{v}^{2}\left(\frac{C_{1 \mathrm{~L} \alpha}}{4 \pi^{2}}+\frac{C_{3 \mathrm{~L} \alpha}}{C_{5 \mathrm{~L} \alpha}^{2} v^{2}+4 \pi^{2}}+\frac{C_{4 \mathrm{~L} \alpha}}{C_{6 \mathrm{~L} \alpha}^{2} v^{2}+4 \pi^{2}}\right) \\
& H_{4}^{*}=\boldsymbol{v}^{2}\left(\frac{C_{1 \mathrm{Lh}}}{4 \pi^{2}}+\frac{C_{3 \mathrm{Lh}}}{C_{5 \mathrm{Lh}}^{2} \boldsymbol{v}^{2}+4 \pi^{2}}+\frac{C_{4 \mathrm{Lh}}}{C_{6 \mathrm{Lh}}^{2} \boldsymbol{v}^{2}+4 \pi^{2}}\right)
\end{aligned}
$$

where $A_{\mathrm{i}}^{*}$ and $H_{\mathrm{i}}^{*}(i=1,2,3,4)$ are the aerodynamic derivatives, which are dependent only on the geometry of the bridge deck section and the reduced velocity, $\boldsymbol{v}$, taken as $U_{\mathrm{m}} / n B$ in terms of the symbols defined earlier.

The aerodynamic derivatives for the deck section of the Ting Kau Bridge are given in the wind tunnel report. ${ }^{16}$ As for other studies, good estimates of the direct aerodynamic derivatives are obtained. However, in view of the scatter of data in the measurement of the cross-aerodynamic derivatives, ${ }^{16}$ their estimates are not considered as reliable. Therefore, in the current study, only the direct aerodynamic derivatives are employed, and this is not uncommon. For example, in the analysis of wind-induced vibration of the Haiwan Bridge and the Humen Bridge, ${ }^{17}$ both located in Guangdong province of China, only the direct aerodynamic derivatives $A_{2}^{*}, A_{3}^{*}, H_{1}^{*}$ and $H_{4}^{*}$ have been taken into account. It has been found that the coupling aerodynamic effects between the vertical and torsional displacements have little effect on the buffeting response of the bridges, and hence the cross-aerodynamic derivatives can be neglected. Similar conclusions have also been found by Simiu and Scanlan. ${ }^{3}$ Based on the non-linear parameter identification algorithm developed by Marquardt, ${ }^{18}$ the $C$ coefficients in equation (13) are then obtained from the direct aerodynamic derivatives via equation (14), and they are given in Table 2. The time histories of self-excited forces acting at the middle of the span between the Ting Kau Tower and the Main Tower are worked out accordingly and given in Fig. 7.

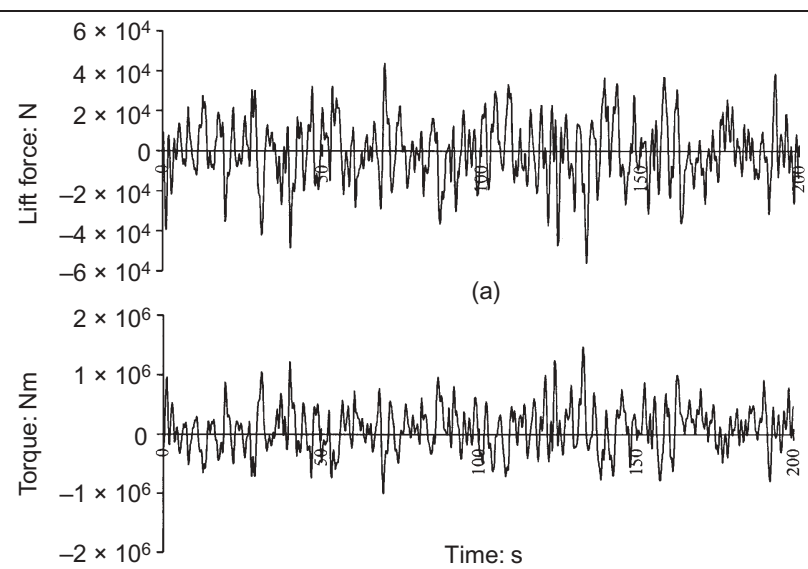

(b)

Fig. 7. Self-excited forces at the middle of the span between Ting Kau Tower and the Main Tower under mean wind velocity, $U_{m}=45.60 \mathrm{~m} / \mathrm{s}$ of 50 -year return period: (a) selfexcited lift force; (b) self-excited torque

\section{BUFFETING RESPONSE ANALYSIS OF TING KAU BRIDGE}

As Ting Kau Bridge is located in a typhoon-prone area, the safety of the bridge against wind action is of great concern. To obtain the displacements and internal forces, and to evaluate the safety performance of the bridge under the action of wind loading, an aerodynamic response analysis of the bridge in the time domain has been performed. In this section, the method of analysis is introduced and the numerical results are presented.

\section{I. Flow chart for aerodynamic response analysis}

A simplified model using a triple-girder model for each carriageway was put forward for the dynamic analysis of Ting Kau Bridge. ${ }^{1}$ The formulation of wind loading acting on the bridge, comprising the equivalent static forces, buffeting forces and the self-excited forces, has been established in previous sections of the present paper. On the basis of the above work, analysis of the wind-induced vibration of the bridge under various mean wind velocities can be carried out, in which both the geometric non-linearity and the aerodynamic windstructure coupling are considered. The effects of axial forces on the flexural stiffnesses are taken into consideration by the initial stress stiffness matrix, and the updated Lagrangian formulation has been adopted to account for the effects of large deflection. The problem is then solved by direct integration using the Newmark method together with the modified Newton-Raphson iterative scheme. The essential steps of the present approach are summarised in the flow chart shown in Fig. 8.

\subsection{Numerical results of aerodynamic response analysis} A comprehensive aerodynamic response analysis of Ting Kau Bridge using the above numerical approach has been carried out. Special attention is paid to the buffeting response of the bridge under the mean wind velocities of $45.60 \mathrm{~m} / \mathrm{s}$ and $53.57 \mathrm{~m} / \mathrm{s}$ at the bridge deck level, 


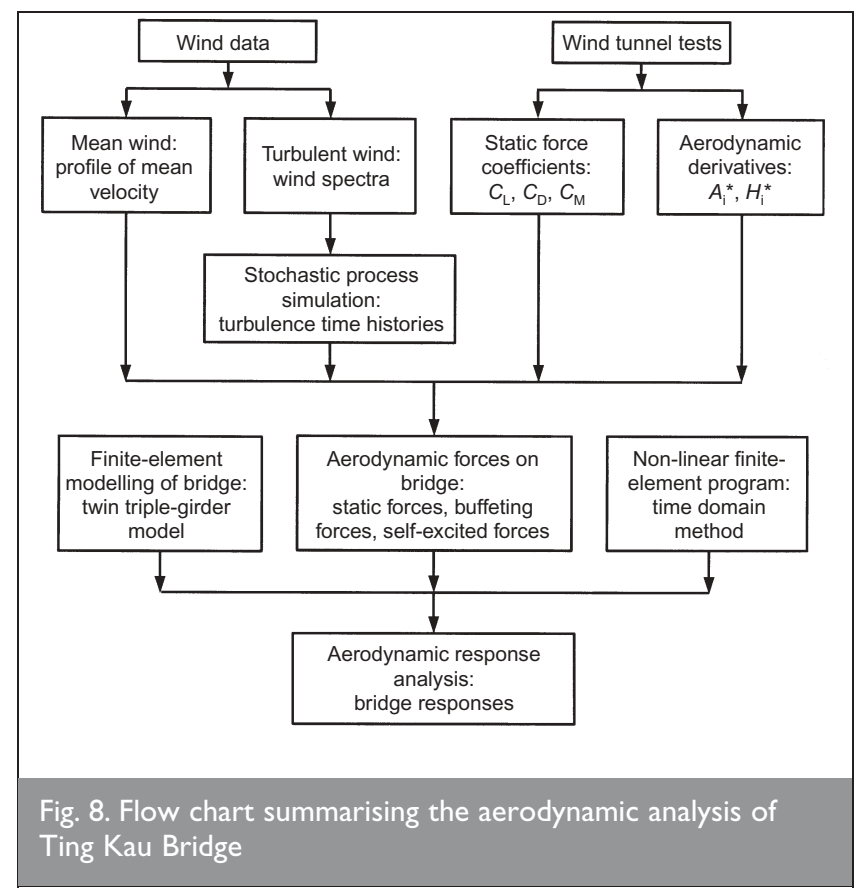

corresponding to return periods of 50 and 120 years respectively. In view of space limitations, only results at selected sections of interest are presented in this paper. In particular, the displacement time histories are calculated at Sections A and D of the bridge deck as shown in Fig. 1, and at the top sections of the three towers. Figs 9, 10 and 11 show respectively the time histories of displacement components at Section A, and at the top sections of Ting Kau Tower and the Main Tower, all under mean wind velocities of $45.60 \mathrm{~m} / \mathrm{s}$ of the 50 -year return period. The peak values of bending

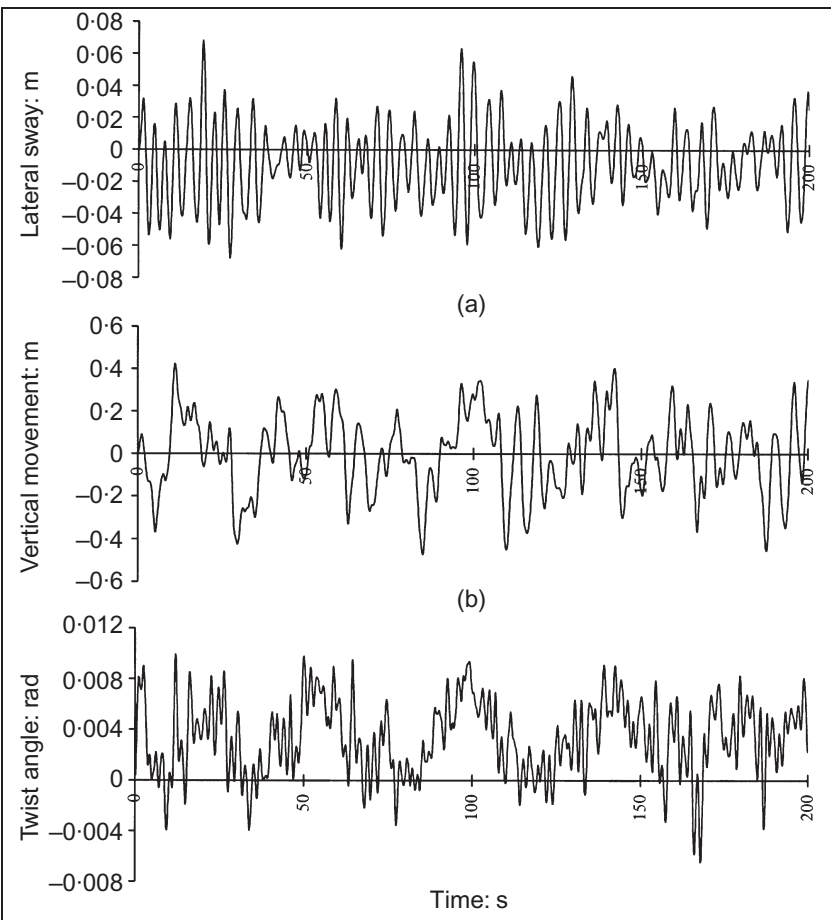

(c)

Fig. 9. Displacements at Section A of bridge deck under mean wind velocity, $U_{m}=45.60 \mathrm{~m} / \mathrm{s}$ of 50 -year return period: (a) lateral sway; (b) vertical movement; (c) twist angle

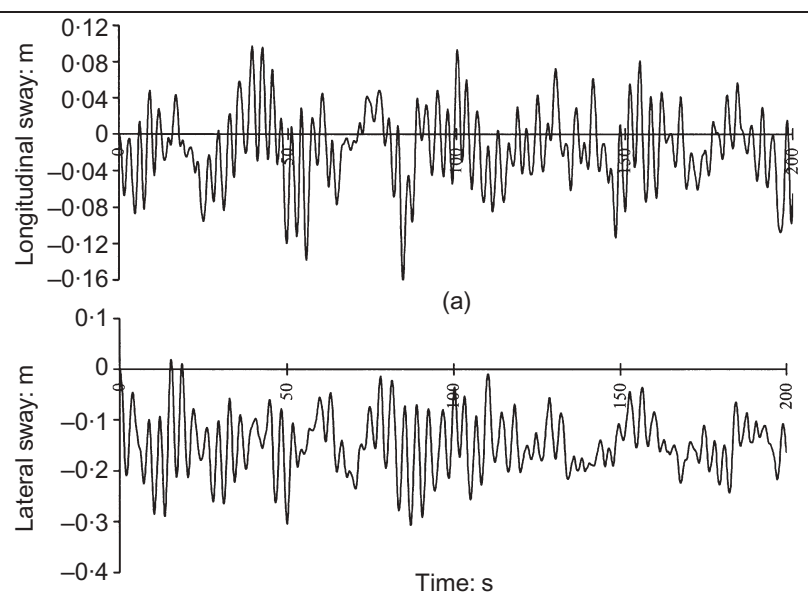

(b)

Fig. 10. Displacements at top of Ting Kau Tower under mean wind velocity, $U_{m}=45.60 \mathrm{~m} / \mathrm{s}$ of 50 -year return period: (a) longitudinal sway; (b) lateral sway

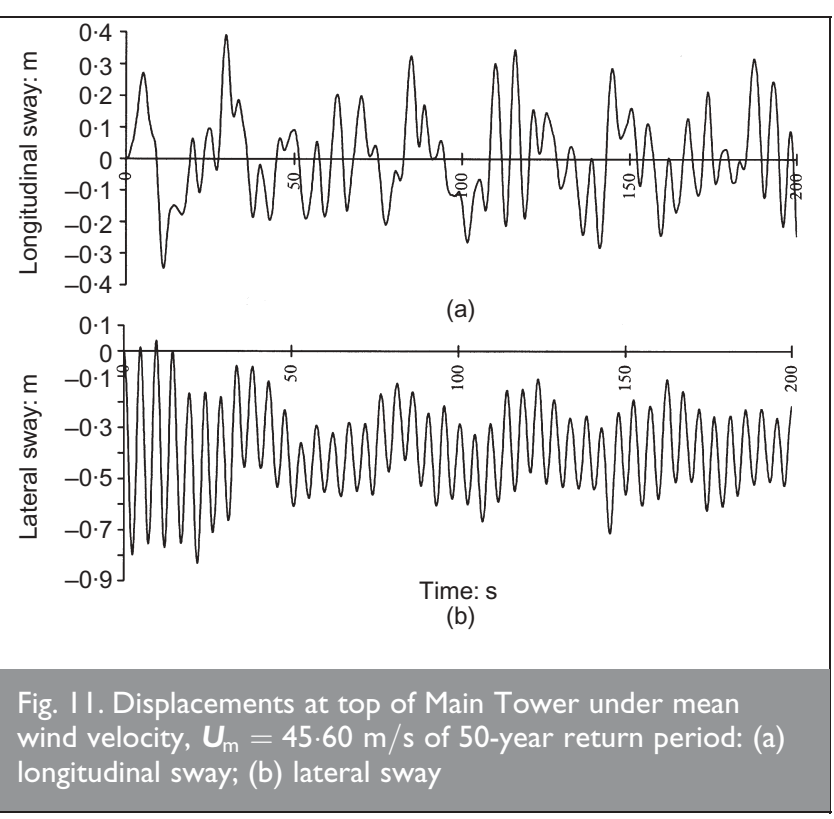

moments of half of the bridge deck at Section A (per carriageway) and those at the bottom sections of the three towers are given in Table 3 and Tables $4-6$ respectively. The results based on the full aeroelastic bridge model, ${ }^{11}$ which have been calibrated against the expected wind conditions at the bridge site are also listed in the above tables for comparison. It can be seen that the theoretical results are basically in agreement with those obtained from wind tunnel tests, except for the values of $\boldsymbol{M}_{\mathrm{x}}$ for the two side towers. Such discrepancies are probably due to the undesirable frictional effects present at the connections between the deck and the end pier/abutment of the full bridge model. The difficulty in providing the prescribed deck restraints at model scale is indeed pointed out in the report on wind tunnel tests. ${ }^{11}$ In addition, the bridge is almost symmetrical, and the values of $\boldsymbol{M}_{\mathrm{x}}$ for the two side towers should be comparable. This is indeed the case for the computed results as shown in Tables 4 and 6, but large discrepancies are observed in the test results.

To study the aerodynamic behaviour of Ting Kau Bridge, a 


\begin{tabular}{|c|c|c|c|c|c|}
\hline \multirow{2}{*}{$\begin{array}{l}\text { Return period: } \\
\text { years }\end{array}$} & \multirow[t]{2}{*}{$\boldsymbol{U}_{\mathrm{m}}: \mathrm{m} / \mathrm{s}$} & \multicolumn{2}{|c|}{$M_{\mathrm{x}}: \mathrm{MN} . \mathrm{m}$} & \multicolumn{2}{|c|}{$\mathbf{M}_{\mathrm{z}}: \mathrm{MN} . \mathrm{m}$} \\
\hline & & Computed & Tested & Computed & Tested \\
\hline $\begin{array}{r}50 \\
120\end{array}$ & $\begin{array}{l}45 \cdot 60 \\
53 \cdot 57\end{array}$ & $\begin{array}{l}1.29 \times 10^{1} \\
1.91 \times 10^{1}\end{array}$ & $\begin{array}{l}1.02 \times 10^{1} \\
1.36 \times 10^{1}\end{array}$ & $\begin{array}{l}5.39 \times 10^{1} \\
1.08 \times 10^{2}\end{array}$ & $\begin{array}{l}5.33 \times 10^{1} \\
8.21 \times 10^{1}\end{array}$ \\
\hline
\end{tabular}

the experimental results for the full bridge model under turbulent flow.

No trend of aeroelastic instability of the bridge whatsoever can be identified over the complete range of wind velocity under study. Tables 7 and 8 show the RMS displacements at sections $\mathrm{A}$ and $\mathrm{D}$ respectively. It is also observed that the theoretical

\begin{tabular}{|c|c|c|c|c|c|}
\hline \multirow{2}{*}{$\begin{array}{l}\text { Return period: } \\
\text { years }\end{array}$} & \multirow[t]{2}{*}{$\mathbf{U}_{\mathrm{m}}: \mathrm{m} / \mathrm{s}$} & \multicolumn{2}{|c|}{$\mathbf{M}_{\mathrm{x}}: \mathrm{MN} \cdot \mathrm{m}$} & \multicolumn{2}{|c|}{$M_{y}:$ MN.m } \\
\hline & & Computed & Tested & Computed & Tested \\
\hline $\begin{array}{r}50 \\
120\end{array}$ & $\begin{array}{l}45 \cdot 60 \\
53 \cdot 57\end{array}$ & $\begin{array}{l}1.99 \times 10^{2} \\
3.70 \times 10^{2}\end{array}$ & $\begin{array}{l}1.60 \times 10^{2} \\
2.05 \times 10^{2}\end{array}$ & $\begin{array}{l}4.67 \times 10^{2} \\
6.07 \times 10^{2}\end{array}$ & $\begin{array}{l}5.01 \times 10^{2} \\
6.98 \times 10^{2}\end{array}$ \\
\hline
\end{tabular}

RMS results basically match those obtained from wind tunnel tests for the mean wind velocities for return periods of 50 years and 120 years.

\section{CONCLUDING REMARKS}

The aerodynamic behaviour of the Hong Kong Ting Kau

\begin{tabular}{|c|c|c|c|c|c|}
\hline \multirow{2}{*}{$\begin{array}{l}\text { Return period: } \\
\text { years }\end{array}$} & \multirow[t]{2}{*}{$\boldsymbol{U}_{\mathrm{m}}: \mathrm{m} / \mathrm{s}$} & \multicolumn{2}{|c|}{$M_{\mathrm{x}}: \mathrm{MN} \cdot \mathrm{m}$} & \multicolumn{2}{|c|}{$M_{\mathrm{y}}:$ MN.m } \\
\hline & & Computed & Tested & Computed & Tested \\
\hline $\begin{array}{r}50 \\
120\end{array}$ & $\begin{array}{l}45 \cdot 60 \\
53 \cdot 57\end{array}$ & $\begin{array}{l}9.49 \times 10^{2} \\
1.19 \times 10^{3}\end{array}$ & $\begin{array}{l}7.56 \times 10^{2} \\
9.80 \times 10^{2}\end{array}$ & $\begin{array}{l}1.57 \times 10^{3} \\
2.25 \times 10^{3}\end{array}$ & $\begin{array}{l}1.38 \times 10^{3} \\
1.86 \times 10^{3}\end{array}$ \\
\hline
\end{tabular}

Table 5. Peak values of bending moments at the bottom of Main Tower

\begin{tabular}{|c|c|c|c|c|c|}
\hline \multirow{2}{*}{$\begin{array}{l}\text { Return period: } \\
\text { years }\end{array}$} & \multirow[t]{2}{*}{$\mathbf{U}_{\mathrm{m}}: \mathrm{m} / \mathrm{s}$} & \multicolumn{2}{|c|}{$M_{\mathrm{x}}: \mathrm{MN} \cdot \mathrm{m}$} & \multicolumn{2}{|c|}{$M_{\mathrm{y}}: \mathrm{MN} . \mathrm{m}$} \\
\hline & & Computed & Tested & Computed & Tested \\
\hline 50 & $45 \cdot 60$ & $2.01 \times 10^{2}$ & $9.69 \times 10^{1}$ & $5.44 \times 10^{2}$ & $5.03 \times 10^{2}$ \\
\hline 120 & $53 \cdot 57$ & $3.53 \times 10^{2}$ & $1.24 \times 10^{2}$ & $7.21 \times 10^{2}$ & $6.57 \times 10^{2}$ \\
\hline
\end{tabular}

series of wind fields corresponding to different mean wind velocities ranging from $20 \mathrm{~m} / \mathrm{s}$ to $70 \mathrm{~m} / \mathrm{s}$ have been investigated. The root mean square (RMS) displacement responses of the bridge deck at Sections $\mathrm{A}$ and $\mathrm{D}$ are given in Figs 12 and 13 respectively. Good agreement is observed for mean wind velocities below $50 \mathrm{~m} / \mathrm{s}$, but the discrepancies tend to increase for higher velocities. This could be attributed to various causes, one being the fact that the self-excited forces are calculated based on the sectional aerodynamic derivatives obtained from section model tests under smooth flow conditions. ${ }^{16}$ The use of turbulent flow has effects on the aerodynamic derivatives, and it usually enhances the aerodynamic stability of bridges. ${ }^{19}$ This may explain why, at higher wind velocities, the computed results appear higher than
Bridge has been studied using a simple twin triple-girder model for the deck. The time histories of wind turbulence along the bridge deck are simulated by a modified spectral representation method based on the available wind spectra and wind characteristics. Using the simulated wind fields and the aerodynamic parameters obtained from wind tunnel tests, the expressions for the aerodynamic forces acting on the bridge are established in the time domain. The aerodynamic response analysis of Ting Kau Bridge is performed in the time domain for various mean wind velocities, taking into consideration both geometric non-linearity and aeroelastic effects. The results show that the bridge behaves well within the range of velocities under consideration, including those for return periods of 50 years and 120 years. Good agreement with results from wind tunnel tests is observed. Such investigations demonstrate that the methodology presented in this paper is reliable and practical for the analysis of wind-induced vibrations of long-span bridges.

\section{ACKNOWLEDGEMENT}

The authors wish to express their thanks to the Director of Highways, Mr Y. C. Lo, for permission to publish this paper. Any opinions expressed or conclusions reached in the paper are entirely those of the authors. 


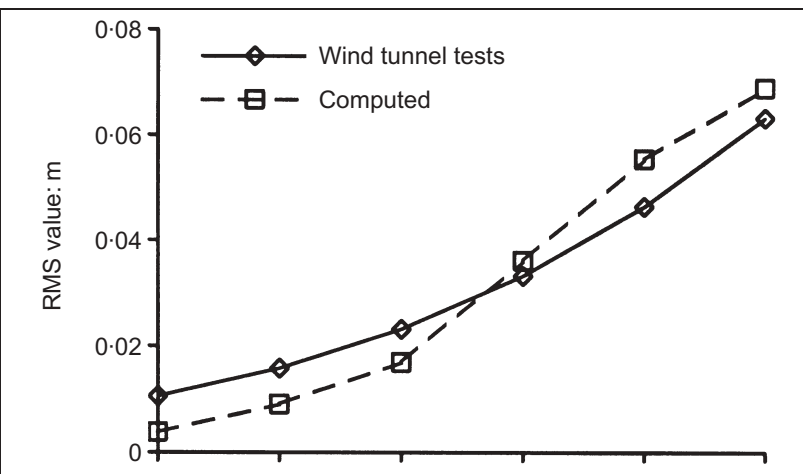

(a)

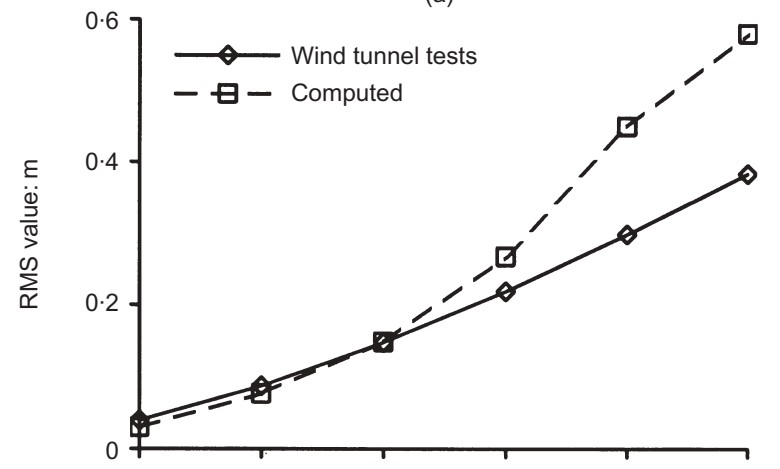

(b)

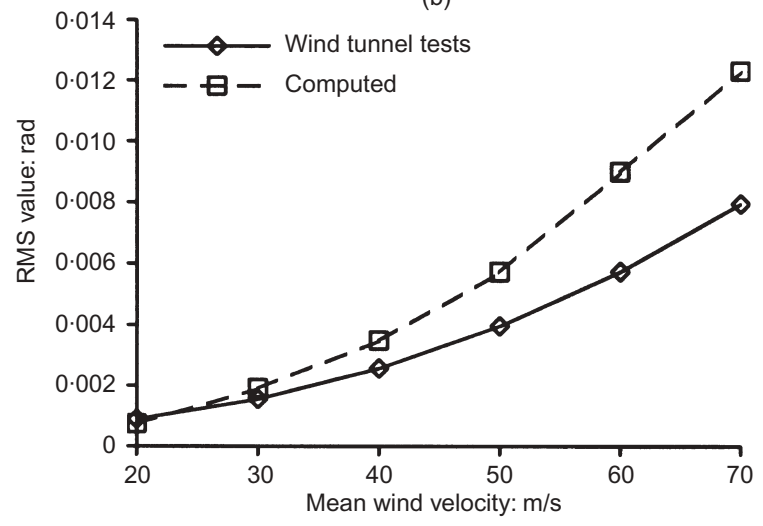

(c)

Fig. 12. RMS displacements at Section A of bridge deck: (a) lateral sway; (b) vertical movement; (c) twist angle

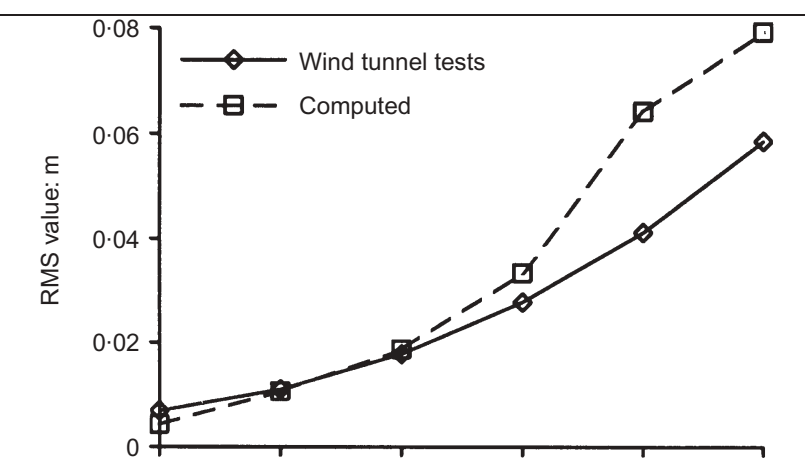

(a)

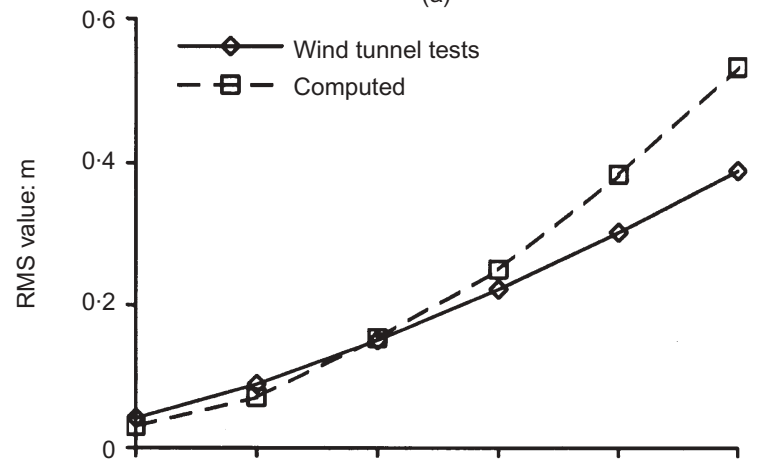

(b)

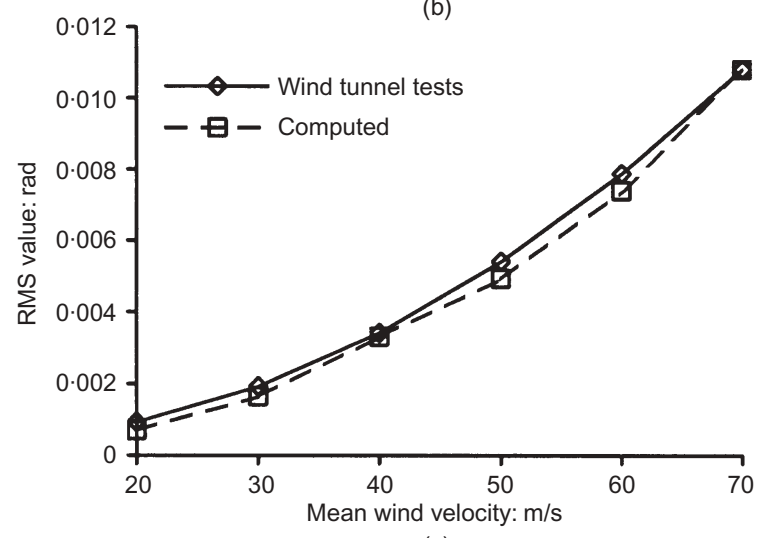

(c)

Fig. I3. RMS displacements at Section D of bridge deck: (a) lateral sway; (b) vertical movement; (c) twist angle

\begin{tabular}{|c|c|c|c|c|c|c|c|}
\hline \multirow{2}{*}{$\begin{array}{l}\text { Return } \\
\text { period: } \\
\text { years }\end{array}$} & \multirow{2}{*}{$\begin{array}{l}U_{\mathrm{m}}: \\
\mathrm{m} / \mathrm{s}\end{array}$} & \multicolumn{2}{|c|}{ Lateral sway: m } & \multicolumn{2}{|c|}{ Vertical movement: $\mathrm{m}$} & \multicolumn{2}{|c|}{ Twist angle: rad } \\
\hline & & Computed & Tested & Computed & Tested & Computed & Tested \\
\hline $\begin{array}{r}50 \\
120\end{array}$ & $\begin{array}{l}45 \cdot 60 \\
53 \cdot 57\end{array}$ & $\begin{array}{l}2.54 \times 10^{-2} \\
4.53 \times 10^{-2}\end{array}$ & $\begin{array}{l}2.84 \times 10^{-2} \\
3.75 \times 10^{-2}\end{array}$ & $\begin{array}{l}1.83 \times 10^{-1} \\
3.09 \times 10^{-1}\end{array}$ & $\begin{array}{l}1.86 \times 10^{-1} \\
2.46 \times 10^{-1}\end{array}$ & $\begin{array}{l}4.43 \times 10^{-3} \\
7.32 \times 10^{-3}\end{array}$ & $\begin{array}{l}3.29 \times 10^{-3} \\
4.54 \times 10^{-3}\end{array}$ \\
\hline
\end{tabular}

\begin{tabular}{|c|c|c|c|c|c|c|c|}
\hline \multirow{2}{*}{$\begin{array}{l}\text { Return } \\
\text { period: } \\
\text { years }\end{array}$} & \multirow{2}{*}{$\begin{array}{l}U_{m}: \\
\mathrm{m} / \mathrm{s}\end{array}$} & \multicolumn{2}{|c|}{ Lateral sway: $\mathrm{m}$} & \multicolumn{2}{|c|}{ Vertical movement: $\mathrm{m}$} & \multicolumn{2}{|c|}{ Twist angle: rad } \\
\hline & & Computed & Tested & Computed & Tested & Computed & Tested \\
\hline 50 & $45 \cdot 60$ & $2.84 \times 10^{-2}$ & $2.29 \times 10^{-2}$ & $1.76 \times 10^{-1}$ & $1.90 \times 10^{-1}$ & $3.97 \times 10^{-3}$ & $4.46 \times 10^{-3}$ \\
\hline 120 & $53 \cdot 57$ & $4.59 \times 10^{-2}$ & $3.20 \times 10^{-2}$ & $3.06 \times 10^{-1}$ & $2.50 \times 10^{-1}$ & $6.18 \times 10^{-3}$ & $6.22 \times 10^{-3}$ \\
\hline
\end{tabular}

\section{REFERENCES}

1. UNIVERSITY OF HONG Kong. Final Report, Ting Kau Bridge: Ambient Vibration Measurement of Complete Bridge. University of Hong Kong, 2000, Report prepared for the Highways Department, Government of the HKSAR.

2. DAVENPORT A. G. Buffeting of a suspension bridge by storm winds. Journal of Structural Division, ASCE, 1962, 88, No. ST3, 233-268.

3. Simiu E. and SCANLAN R. 
H. Wind Effects on Structures. Wiley, New York, 1996, 3rd edn.

4. Kovacs I., Svensson H. S. and Jordet E. Analytical aerodynamic investigation of cable-stayed Helgeland Bridge. Journal of Structural Division, ASCE, 1992, 118, No. 1, 147-168.

5. SAntos J. C., Miyata T. and Yamada H. Gust response of a long span bridge by the time domain approach. Proceedings of Third Asia-Pacific Symposium on Wind Engineering, Hong Kong, 1993, I, 211-216.

6. SHINOZUKA M. and JAN C. M. Digital simulation of random processes and its applications. Journal of Sound and Vibration, 1972, 25, No. 1, 111-128.

7. SHINOZUKA M., YUN C. B. and SEYA H. Stochastic methods in wind engineering. Journal of Wind Engineering and Industrial Aerodynamics, 1990, No. 36, 829-843.

8. YANG W. W., Chang T. Y. P. and ChANG C. C. An efficient wind field simulation technique for bridges. Journal of Wind Engineering and Industrial Aerodynamics, 1997, 67-68, 697-708.

9. CооK N. J. The Designer's Guide to Wind Loading of Building Structures, Part 1. Butterworths, London, 1985.

10. UNIVERSITY OF Hong Kong. Review of Available Data on Wind Characteristics of Hong Kong. University of Hong Kong, 1997, Research report.

11. UnIVERSITY OF WESTERN ONTARIO. Wind Tunnel Report, Aeroelastic Model Study: Ting Kau Bridge and Approach Viaduct. University of Western Ontario, 1995.
12. SCANLAN R. H. and GADE R. H. Motion of suspended bridge spans under gusty wind. Journal of Structural Division, ASCE, 1977, 103, No. ST9, 1867-1883.

13. SCANLAN R. H. Role of indicial functions in buffeting analysis of bridges. Journal of Structural Engineering, ASCE, 1984, 110, No. 7, 1433-1446.

14. SCANLAN R. H. and TOMKO J. J. Airfoil and bridge deck flutter derivatives. Journal of Engineering Mechanics Division, ASCE, 1971, 97, No. EM6, 1717-1737.

15. BuCher C. G. and LIN Y. K. Stochastic stability of bridges considering coupled modes. Journal of Engineering Mechanics, ASCE, 1988, 114, No. 12, 2055-2071.

16. NANYANG Technological University. Wind Tunnel Report: Report on Wind Tunnel Study on the Aerodynamic Derivatives of the Ting Kau Bridge. Nanyang Technological University, Singapore, 1998.

17. LIU C. H., XIANG H. F. and GU M. Three-dimensional nonlinear time-domain buffeting analysis for long span bridges. Journal of Tongji University, Shanghai, China, 1996, 24, No. 4, 380-385, (in Chinese).

18. MARQUARDT D. W. An algorithm for least-squares estimation of nonlinear parameters. Journal of the Society for Industrial and Applied Mathematics, 1963, 11, No. 2, 431-441.

19. SCANLAN R. H. and JoNE N. P. Aeroelastic analysis of cablestayed bridges. Journal of Structural Engineering, ASCE, 1990, 116, No. 2, 279-297.

Please email, fax or post your discussion contributions to the secretary by I February 2004: email: daniela.wong@ice.org.uk; fax: +44 (0)20 7799 1325; or post to Daniela Wong, Journals Department, Institution of Civil Engineers, I-7 Great George Street, London SWIP 3AA. 